\section{Ilustre inominada: Lydia das Dôres Matta e enfermagem brasileira pós-1930}

\section{Eminent but nameless: Lydia das Dôres Matta and Brazilian nursing after 1930}

Paulo Fernando de Souza Campos

Professor, graduação em História e Programa de Pós-graduação Interdisciplinar em Ciências Humanas/Universidade Santo Amaro. São Paulo - SP - Brasil orcid.org/0000-0001-8518-6921

pfcampos@prof.unisa.br

\section{Alessandra Rosa Carrijo}

Professora, graduação em Enfermagem/ Universidade Estadual do Oeste do Paraná. Foz do Iguaçu - PR - Brasil

orcid.org/0000-0002-1691-4240

aleenfermeira@msn.com

Recebido em 12 fev. 2017

Aprovado em 3 maio 2018
CAMPOS, Paulo Fernando de Souza; CARRIJO, Alessandra Rosa. Ilustre inominada: Lydia das Dôres Matta e enfermagem brasileira pós-1930. História, Ciências, Saúde - Manguinhos, Rio de Janeiro, v.26, n.1, jan.-mar. 2019, p.165185.

Resumo

$\mathrm{O}$ artigo analisa o processo de remodelação profissional da enfermagem no Brasil pós-1930. Para tanto, examina a prática docente do ensino superior e a reinserção de mulheres negras na enfermagem profissional por intermédio da biografia de Lydia das Dôres Matta, enfermeira formada na segunda turma da Escola de Enfermagem de São Paulo, como bolsista do Programa de Enfermagem do Serviço Especial de Saúde Pública. Os resultados permitem reflexões em relação à identidade profissional da enfermagem brasileira a partir da trajetória de uma mulher negra, bem como sobre a historiografia da enfermagem no Brasil.

Palavras-chave: história da enfermagem; mulheres negras; identidade profissional.

Abstract

The article analyzes the process of reconstructing the nursing profession in Brazil post-1930. We examine teaching practices in higher education and the reinsertion of black women in professional nursing through the biography of Lydia das Dôres Matta, a nurse trained in the second class graduated from the São Paulo School of Nursing as a scholarship student in the Special Public Health Service Nursing Program. The results allow reflections on the professional identity of Brazilian nursing from the trajectory of a black woman, as well as on the historiography of nursing in Brazil.

Keywords: history of nursing; black women; professional identity. 
A s primeiras alunas afro-brasileiras da Escola de Enfermagem de São Paulo, fundada em 1942 como instituição anexa à Faculdade de Medicina da Universidade de São Paulo, ${ }^{1}$ eram bolsistas oriundas majoritariamente das regiões Norte e Nordeste do Brasil e compunham parte do Programa de Enfermagem mantido pelo Serviço Especial de Saúde Pública (Sesp). ${ }^{2}$

A presença negra na maior escola de enfermagem da América Latina conferia uma visibilidade diametralmente oposta da imagem construída para sua principal personagem "a enfermeira" - e contrariava representações dominantes que a significavam como jovem, branca, culta, em detrimento de outras aparências e perfis tais como os evidenciados por moças do Norte e Nordeste do Brasil que tiveram seus cursos financiados pelo Sesp, isto é, mulheres negras, mulatas e pardas, como se autointitulavam em suas fichas de inscrição e matrícula.

Raramente retratadas, as bolsistas Sesp da Escola de São Paulo podem ser consideradas como ilustres, porém inominadas. Elas compunham o corpo discente da primeira turma a ter os estudos financiados pela organização, entre as quais figuravam Josephina de Mello e Maria de Lourdes Almeida (Souza Campos, 2012, 2013). Mesmo com dificuldades, as primeiras negras a estudarem na Escola de Enfermagem de São Paulo se destacaram na vida profissional, foram importantes, alcançaram méritos e honrarias, apesar de suas trajetórias não figurarem na historiografia produzida por enfermeiros (Barreira, 1997; Porto, Amorim, 2007; Secaf, Costa, 2007).

Esquecidas e inominadas por uma escrita da história glorificadora, construída em torno de grandes eventos e personagens ilustres, a nova história da enfermagem revela outras dimensões das lutas e conquistas femininas, sobretudo no âmbito do ensino superior como cientistas, professoras, orientadoras, consultoras e diretoras de escolas. As mulheres negras que vivenciaram o contexto histórico analisado, caracterizado por sucessivas mudanças no campo da saúde pública no Brasil (Souza Campos, 2008, 2012), redimensionam a historiografia dominante sobre o tema.

A negligência em relação ao protagonismo negro feminino encontra ressonância em outras experiências de mulheres com enormes feitos que morreram no ostracismo, enfermeiras ou não. Entre tantas lutas e confrontos vividos cotidianamente, uma marca indelével ecoa na biografia de Virgínia Leone Bicudo. Sua tese, defendida em 1945, na Escola de Sociologia e Política de São Paulo, intitulada Estudos de atitudes de pretos e mulatos em São Paulo, muito recentemente foi reabilitada, publicada como livro organizado por Marcos Chor Maio (Bicudo, 2010), no qual se demonstra como o debate tornado clássico no campo dos estudos das relações entre brancos e negros encontra primazia na obra dessa intelectual negra. Destaca-se também a experiência de Carolina Maria de Jesus (2015), autora do livro Quarto de despejo: diário de uma favelada, traduzido em vários idiomas e publicado pela primeira vez em 1960. Sua vida e sua obra também exemplificam a trajetória ilustre de uma mulher negra, cujo reconhecimento não anula a memória das exclusões, as experiências vividas como mulher, negra, mãe e pobre.

As mulheres negras no Brasil escravista e pós-emancipação - como não poderia deixar de ser - subverteram naturalizações fabricadas em torno das noções de mulher, classe e raça. Havia uma mobilidade entre mulheres negras, e suas histórias não eram únicas, como 
permite considerar Martha Moreira (1999) ao fazer emergir a memória de uma moça negra que possuía requisitos para o ingresso na melhor escola de enfermagem do Brasil em 1925, mas que teve sua vida acadêmica interrompida por ser negra. Isto é, ainda que em um país racista, ser negro nunca foi ou será uma coisa só ou uma história de mão única (Davis, 2016; Xavier, Farias, Gomes, 2012).

Historicamente, é marcante o vínculo entre cuidado e mulheres negras. Amas de leite, babás, mães pretas e parteiras atuaram poderosamente como cuidadoras na longa história do Brasil e das Américas (Souza Campos, Oguisso, 2013; Velandia Mora, 1995). Nos EUA, a National Association of Colored Graduate Nurses (NACGN) constituía-se em um movimento associativo específico, que reunia enfermeiras negras diplomadas como Mary Elisa P. Mahoney, primeira mulher negra americana diplomada enfermeira pelo New England Hospital for Women and Children, em Boston (Donahue, 1996).

Mary Jane Seacole (1805-1881), "enfermeira jamaicana", destacou-se na Inglaterra vitoriana por suas ações junto às tropas inglesas na batalha de Sebastopol por compor um grupo de mulheres que cuidou de feridos na Guerra da Crimeia (1853-1856), assim como Florence Nightingale (1810-1920) (Mowbrey, 1997), porém, teve menor visibilidade no campo das pesquisas históricas da enfermagem em todo o mundo, ainda que seu busto figure no Florence Nightingale Museum of Saint Thomas Hospital, em Londres.

Estudos históricos no âmbito da enfermagem permitem ampliar as constatações. Em 1923, a Escola Profissional de Enfermeiros e Enfermeiras, núcleo pioneiro vinculado ao Hospício Nacional de Alienados, na cidade do Rio de Janeiro, mantinha cursos de enfermagem que diplomavam homens e mulheres negros, além de ser estruturado no modelo francês de ensino, pautado no manual escrito pelo médico Desiré Margloire Bourneville (Porto, Amorim, 2007). Esse aspecto merece estudos mais verticalizados na pesquisa sobre a história das mulheres negras na enfermagem brasileira, pois pouco se sabe dessas mulheres, quem foram elas, quais suas trajetórias de vida, suas conquistas ou derrotas.

Nessa vertente renovada da pesquisa em história da enfermagem é possível recuperar, por exemplo, a atuação de mulheres negras na Revolução Constitucionalista de 1932, treinadas pela Escola de Enfermagem da Cruz Vermelha Brasileira - filial do estado de São Paulo, a primeira do Brasil. Durante os combates, organizaram entre si um corpo de "enfermeiras" que atuaram nos campos de batalha norte e sul do estado de São Paulo, junto às tropas combatentes formadas por homens e mulheres conhecidos como Pérolas Negras, inclusive como resistência e solidariedade, dada a grande probabilidade de os destacamentos de negros ficarem abandonados à própria sorte (Souza Campos, 2015).

Seja como for, o contexto histórico analisado evoca um intenso movimento de produtos e serviços, a emergência da Segunda Guerra Mundial (1939-1945), o fluir de pessoas e programas promovidos pela Fundação Rockefeller em regiões estratégicas geopoliticamente, assim como a construção de uma nova ideia de nação gestada no governo Vargas (1930-1945). Aliados a outras realidades sociais como a carência de enfermeiros em todo o território nacional, constituíram fatores que ampliaram significativamente as redes de participação americana nas ações de saúde e educação no Brasil (Bertucci, Mota, Schraiber, 2017).

Nesse processo, a atuação do antropólogo Charles Wagley, alto funcionário do Sesp convocado a colaborar nos esforços de guerra junto ao Programa da Borracha, na região 
do Amazonas, é considerada sintomática. Como menciona Regina Érika Domingos de Figueiredo (2014, p.1.424), o cientista esteve à frente da Divisão de Educação Sanitária e destacadamente na "seleção de candidatos do quadro de pessoal do Sesp para receber treinamento especializado ... incluindo a oferta de bolsas de estudo ... o treinamento e formação de pessoal auxiliar para assumir tais atividades". É possível imaginar que Lydia das Dôres Matta, muito provavelmente, participou desse processo.

O alcance da política de boa vizinhança estabelecia determinações estruturais para o campo da saúde e foi um dos motivos para a organização de uma nova escola (des) centralizadora do modelo em vigor. Esse novo estabelecimento de ensino deveria abarcar uma rede nacional de formação profissional que se afastava dos auspícios do cuidar vinculado à religião, por exemplo. Somado à completa escassez de enfermeiros capazes de atender às demandas do país, em processo de mudanças políticas e institucionais, as bolsistas Sesp compunham parte fundamental para a organização da profissão em novas dimensões (Campos, 2006). A formação profissional ampliava não somente o trabalho da enfermagem, mas as determinações do conflito social em todo o território nacional, com especial atenção para as regiões Amazônica e Nordeste. O Sesp foi crucial para o desenvolvimento da profissão e da assistência de enfermagem em todo o Brasil.

A consolidação das instituições republicanas, em confronto permanente com as ordens religiosas, imprime significados legitimadores de defesa territorial em consonância com a política de boa vizinhança entre Brasil e EUA, que reorganiza e supervisona atividades educativas no campo da saúde no contexto analisado. Todavia, como explica Michel de Certeau (1994), o cotidiano é dado pela fabricação de estratégias, isto é, no "jogar desfazendo o jogo do outro". Nessa dinâmica não existem determinações, mas experiências, resistências, arranjos, astúcias, cujos indícios históricos e sociais, não raro, redimensionam quadros mais gerais, no caso, da história da enfermagem no Brasil.

Ainda que enfermeiras americanas liderassem o movimento de formação profissional no Brasil nos anos formadores e pretendessem uma autonomia em relação à medicina e aos médicos, a dominância masculina era pressuposto e regra social à época (Barreira, 1997; Castro Santos, Faria, 2005; Moreira, Oguisso, 2005). A identidade profissional em formação se alinhava não somente aos comportamentos sociais vigentes em relação ao gênero feminino, considerado apropriado para mulheres de boa extração, brancas, bem educadas, mas também em relação à constituição das hierarquias no campo da saúde, politicamente instauradas pela sedução do moderno: o american way of life.

Vale dizer, as decisões não eram tomadas no foro exclusivo das mulheres e, mesmo que articuladas, empoderadas e organizadas, não raro homens decidiam. No caso, as interferências do masculino extrapolavam o âmbito das políticas internas e por elas gestadas. Assim, a constituição de novas regras, que propunham a desobjetivação de gênero, raça e classe no âmbito da formação profissional, bem como da mística da enfermagem relacionada ao cuidar como abnegação, nem sempre eram atendidas, como evidencia a pressão das ordens religiosas e do poder católico no processo de formação da identidade profissional da enfermagem nos primeiros tempos da profissionalização no Brasil (Faria, 2006).

Sem estabelecer uma ideologização entre escolas protagonistas da história da formação profissional da enfermagem no Brasil, tampouco desconsiderar o caráter definidor das 
conquistas promovidas pela implantação do modelo anglo-saxão nos espaços formadores à época, interessa revelar que as relações nem sempre eram amigáveis como evidenciam os indícios de negociações, deslocamentos e tensões permanentes entre as organizações, mas não do tipo conspiratório. Contudo, não é incorreto considerar que lutas simbólicas ocorressem, inclusive, como forma de manutenção da primazia fabricada para a história da enfermagem no Brasil (Porto, Amorim, 2007).

Ainda que rechaçadas pela imposição do padrão proposto como ideal para a enfermagem no Brasil, mulheres negras não somente resistiram como retomaram suas posições no cuidar/cuidado - como profissionais - com a fundação da Escola de Enfermagem de São Paulo (Souza Campos, Oguisso, 2013). Como bolsistas Sesp, atuaram de modo decisivo na reconfiguração da enfermagem brasileira, desenvolvendo o "efeito demonstração" que fundamentou a institucionalização das ciências aplicadas no Brasil (Castro Santos, Faria, 2005).

Desse modo, as constatações que formalizam o presente artigo esboçam a trajetória de uma dessas mulheres, Lydia das Dôres Matta, enfermeira diplomada pela primeira turma de bolsistas Sesp da Escola de Enfermagem de São Paulo, em 1947. Seu itinerário profissional permite redimensionar questões concernentes ao protagonismo de mulheres negras no ensino superior no Brasil, na formação e direção da enfermagem brasileira, cuja história, memória e identidade foram silenciadas.

\section{Lidya das Dôres Matta: "ser de 'Ana Néri"'}

A pequena nota publicada no jornal do Centro Acadêmico da Faculdade de Medicina, da Universidade de São Paulo, conhecido como O Bisturi, permite perscrutar o passado e observar sutilezas das quais os historiadores se servem para desvendá-lo:

Caiu a Bastilha!!! Finalmente, caiu em mãos dos internos, a discutida 'fortaleza' das famosas 'enfermeiras-chefes', que obedeciam ao comando da destemida Clarice, uma das 'Ferrarini Sisters', agora em acentuado declínio. Sentem-se orgulhosos os internos antigos em poder oferecer aos novos de 1947, tamanha dádiva, tal seja o $6^{\circ}$ andar desocupado e desinfetado (Coisas..., abr. 1947).

O episódio, retratado de modo fugidio em uma pequena nota do jornal acadêmico da Faculdade de Medicina, que administrava a nova Escola de Enfermagem, desvela o momento em que alunas da primeira turma Sesp deixaram a residência estabelecida no Hospital das Clínicas da Faculdade de Medicina da Universidade de São Paulo para habitar o novo prédio modernista e recém-edificado para abrigar a escola, cuja construção havia sido pensada também para essa finalidade. Cada aluna passou a ter seu quarto, pois o modelo anglo-saxão de ensino definia o internato como um dos critérios para escolas destinadas à formação de enfermeiras.

Expressões como "desinfetado" e "acentuado declínio" utilizadas por acadêmicos de medicina para narrar o fato da desocupação do andar destinado à moradia de estudantes de enfermagem, como as oriundas de distantes estados do Norte e Nordeste brasileiro, permitem considerar a mentalidade dominante, qual seja, excluir o não representativo ou 
que se desviava do padrão de referência construído para a enfermagem brasileira e que a medicina logrou disseminar e reproduzir.

Desinfecção e rebaixamento relacionavam a presença de moças negras que ocuparam o andar por mais de três anos com noções de sujidade e inferioridade. Oriundas de estados pobres e distantes das grandes capitais do Brasil, enviadas a São Paulo para estudar enfermagem como bolsistas Sesp, as alunas foram desprestigiadas. Tal perspectiva reproduzia discursos que desconsideravam as origens étnicas das bolsistas. Sintomaticamente, o ano de publicação da nota no jornal acadêmico corresponde ao de formatura da primeira turma de bolsistas Sesp, que diplomou mulheres preparadas para disseminar a nova enfermagem brasileira em seus locais de origem, entre as quais as primeiras alunas negras do que é hoje a Escola de Enfermagem da Universidade de São Paulo.

Inferências dessa natureza encontram sustentação em outro episódio, do mesmo modo fugidio mas revelador do ponto de vista da intolerância vivida por afrodescendentes no âmbito da institucionalização das ciências aplicadas no Brasil, bem como da reconfiguração da enfermagem brasileira. Conforme destaca Amália Corrêa de Carvalho (1992, p.102), bolsistas Sesp, ao chegarem à escola e "por conta de um problema qualquer", foram impedidas por veteranas de adentrar no prédio recém-inaugurado, pois essas não permitiram que "as moças fossem incorporadas ao grupo de estudantes já matriculados ... de certa maneira ficaram isoladas até que a presidente do Centro Acadêmico resolvesse o problema com D. Edith, que imediatamente solucionou, determinando a matrícula das três". Diante de tais indícios, o que poderia ter levado à recusa? Qual o teor da conversa travada entre a diretora da escola, Edith de Magalhães Fraenkel (1889-1968), e as veteranas Amália Corrêa de Carvalho e Zuleika Kanneblay, responsáveis pelo Centro Acadêmico? Como permitem considerar os indícios históricos, as três moças impedidas pelas veteranas eram Josephina de Melo, Maria de Lourdes Almeida e Lydia das Dôres Matta.

As alunas veteranas da primeira turma da Escola de Enfermagem de São Paulo, composta por moças ricas, filhas de uma pequena elite de fazendeiros e comerciantes de São Paulo, oriundas em sua maioria do interior do estado, foram selecionadas para rapidamente assumirem a docência na mesma escola (Santiago, 2011; Carvalho, 1980). A chegada de bolsistas Sesp, aliada à representação dominante, levaram a surpresa do improvável e fizeram com que as veteranas assumissem posturas hostilizadoras frente às recém-chegadas, moças negras, pardas, morenas, com perfis destoantes das poucas alunas da escola recém-instaurada, entre as quais as contratadas para compor o quadro docente assim que retornassem de estudos pós-graduados nos EUA (Souza Campos, Oguisso, 2008). Como reitera Stuart Hall (2009), a prevalência da noção de identidade fixa excluía padrões diferenciados ou em oposição ao assumido como ideal, classificando rigidamente os sujeitos e cristalizando estereótipos.

O problema gerado pelo ingresso de alunas negras na Escola de Enfermagem de São Paulo seguramente reflete vicissitudes de propostas políticas instauradas por Getúlio Vargas, identificadas como populistas e voltadas à inclusão do brasileiro comum nos serviços públicos então inaugurados e exigidos pela organização política do Estado republicano, mesmo que essas fossem tratadas com o segregacionismo costumeiro, largamente praticado nos regimes anteriores. Entretanto, o episódio implica considerar que, no contexto histórico 
pós-1930, novas redes de sociabilidades foram estabelecidas no Brasil, nas quais negros foram inseridos na sociedade mais ampla, passando a assumir posições superiores na administração pública, mesmo que na subalternidade e no obscurantismo.

Lydia das Dôres Matta compunha o grupo de negras diplomadas pela escola de maior projeção na enfermagem brasileira e na América Latina. Sua história profissional tem início com a assinatura do Termo de Contrato Sesp, que possibilitou seu ingresso na segunda turma do Curso Básico de Enfermagem, da Universidade de São Paulo, primeira turma de bolsistas Sesp. O teor jurídico do contrato estipulava que "a contratada se compromete a frequentar o referido Curso, apresentando-se ao Sesp, em Belém, Pará, logo que tenha terminado o mesmo ou em caso de desligamento por qualquer motivo". O acordo reiterava, "a contratada se obriga a trabalhar para o Sesp pelo prazo mínimo de 2 (dois) anos, a partir da data de sua apresentação em Belém, após a conclusão do Curso, no local para onde for designada pelo Serviço", cláusula existente em todos os termos de outorga de bolsas Sesp, o que consubstanciava o efeito demonstração objetivado pelo Programa de Enfermagem da Fundação Rockefeller (Termo..., fev. 1942).

A imediata contratação para os serviços de saneamento e desenvolvimento da assistência de enfermagem nas regiões Norte e Nordeste incluía ministrar aulas em escolas apoiadas pelo Sesp, assegurando assim a participação direta de bolsistas no desenvolvimento e gestão de políticas públicas de saúde no Brasil pós-1930. Caso concluíssem o curso, as atividades inerentes ao termo de contrato projetavam um futuro promissor como enfermeiras-chefes às moças "de boa extração", treinadas para ocupar cargos profissionais imprescindíveis ao Programa de Enfermagem do Sesp em todas as regiões do Brasil, com especial atenção às regiões Norte e Nordeste, nas quais eram mantidas bases americanas em constante fluxo de produtos e pessoas como enfermeiras, socorristas, padioleiros e voluntários preparados pela Cruz Vermelha Brasileira para o front interno durante a Segunda Guerra Mundial, além do efetivo do exército americano (Oguisso, Dutra, Souza Campos, 2008).

Como outras alunas negras, Lydia das Dôres Matta era uma moça de hábitos discretos e com poucos recursos, características que a afastavam das veteranas da escola. Sua presença evocava sensibilidades consoantes a uma permanência histórica: a exclusão dos negros na sociedade brasileira. Entretanto, assim como no mundo social mais amplo, essa não era uma condição, uma via de mão única como permite considerar a trajetória de Josephina de Melo, filha de uma pequena elite de negros barbadianos protestantes da cidade de Manaus e que ingressa com Lydia e Maria de Lourdes na mais nova e moderna escola de enfermagem do Brasil no contexto (Souza Campos, Oguisso, 2013).

Os registros indicam que Lydia se identificava como "parda", católica, filha de um imigrante português naturalizado brasileiro e que mantinha residência na cidade de Belém, estado do Pará, região Norte do Brasil. Sua mãe, Zeferina das Dôres Matta, negra, trabalhava como costureira e conduzia a vida simples de uma família numerosa, na qual Lydia cresceu alimentando o sonho de um dia "poder ser de Ana Néri" (sic) (Matta, 4 dez. 1956, s.p.), personagem que evoca tanto a memória da voluntária da Guerra do Paraguai (1864-1870) quanto da escola considerada padrão na formação de enfermeiras no Brasil.

A atração pelo discurso patriótico consubstanciou a formação profissional da jovem paraense. Suas memórias, descritas nos registros de sua passagem pela escola, evocam a 
escrita de si: "há anos, quando fazia o $3^{\circ}$ ano do curso primário, li no $3^{\circ}$ Erasmo Braga uns versinhos sobre Ana Néri (sic). Na minha pouca idade admirei esta alma elevada, esta mulher humanitária; senti o desejo de dedicar-me a tão sublime missão". Seu texto continuava demonstrando que sua infância, mesmo trágica, primava pela boa educação, pois reiterava "desejo este, que desapareceu aparentemente com a morte de meu pai, ficando minha família impossibilitada de custear qualquer filho em estudos superiores" (Matta, 4 dez. 1956, s.p.). Ao destacar os aspectos acima descritos em sua ficha de inscrição como resposta à questão sobre os motivos da escolha pela profissão, a bolsista desvela estrategicamente que sabia manejar as palavras e construir uma memória de si mesma que valorizasse sua entrada na escola.

O panorama familiar, observado pela ocupação de seus três irmãos homens - maquinista, foguista, chofer - possibilita conhecer a condição social de sua família. Com uma irmã professora, outra diplomada em "escola profissional" e quatro irmãs estudantes, uma das quais em um curso de enfermagem, a família ampliava possibilidades de distinção e ascensão social. Lydia não era uma moça rica, mas educada e com uma vida acima da linha da pobreza comum à maioria dos negros no Brasil.

Os indícios históricos sugerem que se tratava de uma moça tímida, que não gostava de aparecer. Como identificado no material documental analisado, em específico as fotografias, Lydia raramente era retratada ou se deixava retratar, posicionando-se sempre de modo a esconder-se entre as demais alunas quando se deixava fotografar em grupo. Contudo, ao apresentar os motivos que a levaram a optar pela enfermagem, a documentação mostra uma jovem decidida a perseguir seus ideais de menina e, ao mesmo tempo, uma mulher atenta às possibilidades da profissionalização e ascensão social, sobretudo para uma mulher negra. Os registros que apresentam a passagem de Lydia pela Escola de Enfermagem de São Paulo permitem descrevê-la como uma mulher disposta a enfrentar as dificuldades da formação profissional, do mundo do trabalho, da atuação na enfermagem, mesmo que para isso tivesse que suportar intransigências e desrespeitos ou sofrer calada o racismo permanente nas relações entre brancos e negros no Brasil.

A experiência de Lydia não implica pensar que se tratava de uma mulher sujeita à "morte em vida". O fato de ser uma moça simples, que não se deixava fotografar, de poucos amigos e que morre silenciosamente não a torna uma solitária; ao contrário, educou muitos, não teve filhos, mas criou sobrinhos e agregados, mobilizou-se politicamente junto à Associação Brasileira de Enfermagem (Aben), assumiu a direção da primeira Escola de Enfermagem no Brasil, atuou no Programa de Enfermagem do Sesp no Amazonas e no Rio de Janeiro e foi para Brasília, cidade para a qual transferiu residência, e trabalhou com o movimento da Novacap, ou seja, tratava-se de uma mulher decidida, que reconhecia as possibilidades que a enfermagem lhe dava.

Para além das brechas proporcionadas pela política varguista, seu interesse estava na atuação profissional, na manutenção e desenvolvimento da enfermagem, profissão à qual dedicou sua vida e travou poucas, mas boas relações. Ainda que pouco reconhecida, raramente estudada ou referenciada no processo histórico da arte e ciência do cuidado no Brasil, seus comportamentos não tornaram Lydia uma mulher que viveu em extrema solidão, mas certamente uma mulher que criou seus próprios caminhos. 
A boa formação educacional favoreceu o ingresso na Escola de Enfermagem de São Paulo, pois havia concluído o primário no Grupo Escolar Barão do Rio Branco e o Curso Normal no Instituto de Educação, escolas tradicionais da cidade de Belém, atingindo notas finais acima da média e obtendo no primário "4 distinções e louvor" (Matta, 4 dez. 1956). Do mesmo modo, seu histórico indica que havia concluído o curso de datilografia e socorrista da Cruz Vermelha, competências valorizadas no contexto da Segunda Guerra Mundial. Seus registros apresentam uma única reprovação no curso secundário, justificada pelo "número de faltas por ocasião da morte de meu pai, que me impossibilitou de estudar", contudo, o fato não maculava seu histórico exemplar (Matta, 4 dez. 1956).

Sua vida social pode ser retratada como esmerada por princípios nobres, cultos, como permite entrever a informação que segue: "deixei o curso de piano em 1934 por falta de recurso: neste ano faria o $4^{\circ}$ ano se tivesse podido continuar" (Matta, 4 dez. 1956, s.p.), acrescentando certo glamour à ficha de admissão, ao mesmo tempo que agregava valor à sua trajetória pessoal, arranjos sociais que Lydia sabia manejar. Significativos, os esforços de Lydia em mostrar-se competente, inteligente, culta e acima da média, com uma história de vida pontuada pela excelência e valores nobres, não se tratava apenas de mera constatação. Ao contrário, ao destacar suas qualidades, Lydia permite supor que reconhecia a mentalidade recorrente, vale dizer, que pessoas não brancas "deveriam" comprovadamente atingir excelência como critério utilizado para inclusão social e profissional. Ainda que instauradas na violência simbólica desqualificadora de negros, as ações de Lydia permitem supor que ela jogava desfazendo o jogo do outro.

Mesmo com dificuldades financeiras, a jovem paraense conhecia cidades importantes não somente de sua região, como Manaus, Amazonas, mas outras capitais como as do Rio de Janeiro e de São Paulo, na região Sudeste do Brasil, indícios que possibilitam considerar um possível cosmopolitismo provocado por sua participação nos arranjos de guerra, ainda que no front interno. Sua ficha de inscrição indica que gostava de "literatura sacra e profana" e dedicava-se a trabalhos manuais, atributos qualificadores para uma postulante a enfermeira e necessários para o ingresso na escola.

Sua biografia demonstra que, no contexto da seleção como bolsista Sesp, trabalhava como professora primária, função da qual se afastou "para continuar um curso de Enfermagem completo, arrematando o de Socorrista Voluntária" (Matta, 4 dez. 1956, s.p.) promovido pela Cruz Vermelha Brasileira, em Manaus, destacando-se entre as demais postulantes. Os registros acrescentam que "nesta ocasião, sentindo renascer o sonho da infância, alistei-me em Manaus como Socorrista Voluntária da Cruz Vermelha com o fito de assim poder ser de Ana Néri" (Matta, 4 dez. 1956), ícone humanitário, considerada patrona da enfermagem brasileira por sua experiência como voluntária do Exército Nacional na Guerra do Paraguai (1864-1870). Comprovadamente, seu histórico atingia a excelência necessária para ser admitida na maior escola de enfermagem da América Latina.

Não coincidentemente, o histórico profissional de Lydia das Dôres Matta destaca o trabalho realizado junto ao Hospital Evandro Chagas, construído na cidade de Belém como centro de pesquisas de excelência e vinculado ao Instituto Oswaldo Cruz, Manguinhos, Rio de Janeiro. O vestígio permite entender um pouco melhor os caminhos percorridos por Lydia, que reconhecia na enfermagem sua verdadeira vocação, assim como as possibilidades 
de ascensão social que a formação profissional favoreceria, de mobilização geográfica e atuação em serviços públicos demandados pela politica varguista e que a profissionalização acarretava, inclusive como estratégia de uma guerra sem guerra, como caracteriza Roney Cytrynowicz (2000).

Ao realizar o esboço histórico do Instituto Evandro Chagas, Leônidas Deane (1986) reitera o destaque conferido no período ao instituto. Referência nos estudos das moléstias das regiões Norte e Nordeste no Brasil, as pesquisas promovidas pelo instituto ampliavam a prestação de serviços no campo da saúde pública, além de adensar as pesquisas em torno dos temas da microbiologia e das doenças tropicais. Estudos desenvolvidos no instituto agregavam nomes importantes da nova geração de cientistas nacionais e eram dirigidos por Evandro Chagas, filho de Carlos Chagas, diretor do Instituto Oswaldo Cruz, instalado na cidade do Rio de Janeiro.

A primazia intelectual do grupo pode ser avaliada pela composição da comissão encarregada em estudar a leishmaniose visceral americana "da qual faziam parte Aristides Marques da Cunha, Gustavo de Oliveira Castro e Leoberto de Castro Ferreira, aos quais se incorporou depois o argentino Cecílio Romaña", chefiada por Evandro Chagas, todos cientistas renomados (Deane, 1986, p.48). Em 11 de novembro de 1936, desdobramentos da comissão possibilitaram a fundação do Instituto de Patologia Experimental do Norte (Ipen). Antonio Acatauassu Nunes Filho, catedrático de microbiologia da Faculdade de Medicina do Pará, foi o primeiro diretor, sucedido por Antonio Emiliano de Souza Castro, catedrático de doenças tropicais, consubstanciando o círculo científico que se instalava em Belém, muito provavelmente conhecido por Lydia, cujos indícios históricos e sociais permitem considerar que seus interesses e atuações a aproximavam do grupo, mesmo como expectadora, e não protagonista.

A essa equipe local vieram juntar-se pouco tempo depois, como membros do já citado grupo do Instituto Oswaldo Cruz, outros jovens médicos recém-formados no Rio de Janeiro: Octávio Mangabeira Filho, entomólogo por vocação, Madureira Pará, patologista, e o veterinário Geth Jansen, além de uma estudante da Faculdade de Medicina do Pará, Maria José von Paumgartten (depois Maria Paumgartten Deane). Evandro tinha então 32 anos e quase todos os membros de sua equipe tinham de 20 a 26 anos (Deane, 1986, p.48).

Nesses termos, a referência conferida por Lydia em relação ao trabalho desenvolvido junto ao Hospital Evandro Chagas permite considerar que a bolsista manteve contato com médicos e cientistas de renome, que desenvolviam pesquisas em torno de endemias como calazar, malária, leishmaniose tegumentar, bouba, filariose e verminoses intestinais. Eles necessitavam de equipes para acompanhar atendimentos e auxiliar serviços de coleta que colaboravam com o desenvolvimento das pesquisas científicas no campo da saúde pública. Muito provavelmente, Lydia estabeleceu boas relações e conheceu uma pequena elite intelectual, pois sabia que a possibilidade de ascensão social e profissional implicava manter redes de influências que caracterizavam o espírito da época, povoado por imagens da Segunda Guerra Mundial e fabricadas no front interno.

Nesse ponto é preciso destacar que as análises empreendidas não consideram haver uma correlação entre os alcances de Lydia como enfermeira e o feminismo negro. Ainda 
que sua biografia evoque uma mulher negra que não mediu esforços para ingressar na enfermagem, não é possível afirmar que suas ações estivessem atreladas ao movimento negro. A ideologia do mérito que prevaleceu nos anos de sua formação em São Paulo (Andrews, 1998) acompanha sua história pessoal, na medida em que, após diplomada, foram esses os motivos que levaram Lydia a ser convidada a dirigir a Escola Alfredo Pinto, mas essa condição não a subjuga nem diminui sua trajetória.

O debate sobre honra, respeitabilidade e cidadania concernentes ao conceito de "quase cidadão" que pauta a coletânea organizada por Flavio dos Santos Gomes e Olívia Maria Gomes da Cunha (2007), trazido para o caso em análise, encontra uma especificidade. O aceite da bolsa Sesp significava atuar no Programa de Enfermagem, isto é, assim como Lydia, todas as bolsistas seriam incorporadas ao serviço de saúde pública em suas regiões de origem como servidoras públicas, vinculadas ao governo federal, para atuar em programas desenvolvidos em parceira com os EUA. O impacto da formação profissional como bolsista Sesp na vida de Lydia não era por ela desconhecido; desse modo, a faceta em relevo aponta uma mulher negra inominada construindo suas próprias noções de afirmação e protagonismo.

Jornais de época permitem compreender o contexto no qual a bolsista do Sesp se deslocou de Belém para São Paulo a fim de realizar o curso de enfermagem. Jornais que circulavam na capital paulista informavam seus leitores sobre as consequências da Segunda Guerra Mundial, bem como as ações do governo de Getúlio Vargas, sobretudo as relações estabelecidas com os EUA. Manchetes como "Bombas voadoras fornecidas ao Brasil" (Bombas..., 24 jun. 1947) remetiam o leitor para um universo polissêmico, balizado pelos dramas e horrores provocados pelas imagens de guerra, que mobilizava brasileiros e elevava o patriotismo, assim como pela política da boa vizinhança com os EUA.

Os esforços de Lydia das Dôres Matta revelam a resignação de uma jovem brasileira que reconhecia nas vicissitudes da guerra oportunidades fabricadas pelo nacionalismo, bem como as rejeições que teria de enfrentar:

Passou-se o tempo, e veio a Guerra com sua catástrofe aterradora e a Pátria atraiçoada por inimigos, chamou os filhos para corajosamente defendê-la - mas os filhos não podiam seguir sem alguém que os confortasse nos momentos supremos da luta! E ela, a Pátria querida, bradou chamando também as filhas dedicadas para ajudar a minorar o sofrimento dos que lutam pela vitória do Brasil. E nesta ocasião, sentindo renascer o sonho da infância, alistei-me em Manaus como Socorrista Voluntária da Cruz Vermelha com o fito de assim poder ser de Ana Néri (sic): mas os desígnios de Deus dirigiram os meus passos para uma escola quão aprimorada quanto à do meu sonho de criança embora seja verdade que a $1^{\mathrm{a}}$ impressão contribuía para formar no aluno o novo meio que tem a enfrentar. E no novo ambiente em que me encontro, embora saiba que é a perfeita técnica da enfermagem moderna, num conjunto de aprimorados dirigentes e escolhidos mestres, não deixo de sentir uma amargura embora injusta, de não poder ter sido aluna da escola Ana Néri (sic), apesar de que a Escola em que me acho, nada deixa a desejar. Lydia das Dôres Matta, 4 abr. 1944 (Ficha..., fev. 1942).

Formada para disseminar o modelo preconizado pela enfermagem norte-americana, ex-aluna da Escola de Enfermagem de São Paulo, Lydia havia comprovado sua capacidade 
e adquirido respeito. Atingir a excelência - como ocorreu - indicava que possuía atributos intelectuais e competência técnica que a capacitava para assumir liderança. Lydia tornou-se uma das poucas alunas que mantinham estreita relação com a diretora Edith de Magalhães Fraenkel, considerada uma mulher austera, de poucos amigos e bastante rigorosa.

O histórico de Lydia das Dôres Matta chegou a ser traduzido para a língua inglesa, como exigia a documentação requerida para candidatas a bolsas em escolas norte-americanas. Mesmo não conquistando uma das vagas oferecidas pela Fundação Rockefeller para cursos pós-graduados nos EUA e Canadá, a constatação da possibilidade, evidenciada pela tradução do currículo, desvela a qualificação alcançada por Lydia. Ao reconhecer as possibilidades que a Escola de Enfermagem de São Paulo propiciou ao seu futuro profissional, não mediu esforços para conquistar a excelência acadêmica, mas também incorporar traquejos sociais e comportamento cosmopolita.

A nova condição social conferida após sua profissionalização a desvelava como uma mulher emancipada, moderna, formada pela escola de maior projeção na América Latina, aluna de professores ilustres como Maria Rosa Sousa Pinheiro, Glete de Alcântara, Ella Hasenjaeger, Yolanda Linderberg Lima, João Carvalhal Ribas, entre outros. A formação fez de Lydia uma das poucas enfermeiras com formação superior no Brasil naquele contexto. Diploma de enfermeira e experiência de anos vividos na capital bandeirante, identificada como "locomotiva do país", permitiram atuação decisiva no âmbito do ensino da enfermagem brasileira; contudo, suas conquistas foram sufocadas e pouco retratadas entre os que se dedicam ao estudo da história da enfermagem.

A importância atribuída a sua formação emerge do registro Resumo dos Estágios Práticos, formulário de acompanhamento de alunas preenchido por professoras e supervisoras, cujas notas indicam que Lydia atinge pontuação sempre acima de nove, com menção à classificação "excepcional" para o estágio Enfermagem de Saúde Pública. A média de seu trabalho prático $(9,5)$, comparado ao curso teórico $(6,85)$, permite constatar que sua formação se voltou à área assistencial, talvez porque a literatura utilizada na Escola de Enfermagem de São Paulo, escrita em língua inglesa, dificultava os estudos teóricos exigidos. Outro dado emerge de seu histórico escolar e permite pontuar sua menor nota $(5,5)$ em psicologia individual e educacional e higiene mental, ministrada por Noemi Rudolfer, médica da Faculdade de Medicina (Resumo..., jan. 1946, s.p.). A baixa produtividade na disciplina, mesmo considerada aluna excepcional em estágios clínicos, permite considerar que temáticas abordadas afastavam interesses de quem poderia sentir-se retratada por manuais existentes, utilizados didaticamente à época, mas fundados em estudos pautados em determinismos raciais, biotipológicos, que identificavam negros como degenerados e criminosos natos, biologizando a opressão vivida fundamentamente por mulheres negras, como reitera Angela Davis (2016).

Com o término do curso na Escola de Enfermagem de São Paulo, a jovem paraense é recrutada pelo Sesp para atuar como professora, em Belém, local em que permaneceu por oito anos trabalhando para o Amazon Program em atividades que incluíam ministrar cursos e disciplinas em escolas. Registros apontam seu retorno para Belém como um momento importante, pois ser formada pela Escola de Enfermagem de São Paulo e com estágios no Hospital das Clínicas - empreendimentos cuja visibilidade no âmbito da assistência à saúde 
atingia a América Latina - fazia da mais nova enfermeira uma profissional possuidora de conhecimentos atualizados, distante da imagem tímida da moça que, ao chegar a São Paulo, sentiu-se rechaçada. Ao contrário, a convocação para atuar como professora em Belém, efetivada pelo Sesp, transformou sua trajetória de vida. Titulada enfermeira, Lydia assumiu posição de destaque e liderança no campo do ensino e formação da enfermagem no estado do Pará, mas também no Rio de Janeiro, capital da República, como atestam os registros históricos compulsados durante a pesquisa no Laboratório de Pesquisa de História da Enfermagem da Universidade Federal do Estado do Rio de Janeiro (Laphe/Unirio).

Os indícios históricos de sua experiência profissional reiteram que, em 1956, por decreto assinado pelo presidente da República, Juscelino Kubitschek de Oliveira (19561961), Lydia das Dôres Matta assumiu na cidade do Rio de Janeiro a direção da Escola de Enfermagem Alfredo Pinto, estabelecimento vinculado ao Serviço Nacional de Doenças Mentais (EEAP/SNDM), historicamente a primeira escola de enfermagem do Brasil. A experiência consubstanciou sua trajetória profissional e redimensionou, ainda mais, sua história pessoal. A decisão governamental implicaria mudanças significativas na história de vida de Lydia, pois conferia status social e posição de destaque junto à enfermagem na capital do Brasil. A correspondência encaminhada para os procedimentos regulatórios de sua nova função, datada de 4 de dezembro de 1956, caracterizada como uma solicitação, é um indicativo desse processo:

Senhor Diretor: Comunico a V.S. que tomei posse e assumi a direção desta Escola a 26 de outubro próximo findo, solicitando a V.S. comunicar a Delegacia Federal de Saúde da $3^{\text {a }}$ Região - Belém, não só minha designação para a referida função, como também a remessa da frequência, a fim de que possa receber os proventos a que tenho direito, como funcionário lotado naquela repartição. Solicito, outrossim, a V.S. comunicar à Divisão do Pessoal do Ministério da Saúde, a fim de que a mesma providencie para que o crédito não seja distribuído àquela Delegacia no ano vindouro. Aproveito a oportunidade para apresentar a V.S. meus protestos de estima e consideração. Lydia das Dôres Matta. Diretora da EEAP (Matta, 4 dez. 1956).

Enviar correspondências a pessoas de influência no âmbito da saúde ou que pudessem favorecer e apoiar sua gestão foi uma das primeiras iniciativas da nova diretora da Escola de Enfermagem Alfredo Pinto, entre os quais, Odilon Vieira Gallotti, diretor do Hospital Pedro II, Rio de Janeiro, cujo ofício encaminhado no dia 23 de novembro de 1956 dizia: "Acuso recebimento do seu ofício n.401, datado de 12 do corrente, no qual me comunica ter assumido a direção da Escola de Enfermagem Alfredo Pinto. Agradeço, honrado, a distinção e faço votos para que sua permanência na direção da EEAP seja de grande proveito para a mesma. Aproveito para apresentar-lhe meus protestos de estima e apreço" (Gallotti, 23 nov. 1956). Ainda que politicamente estabelecida, a gestão de Lydia na Escola de Enfermagem Alfredo Pinto é marcada por turbulências que merecem ser aprofundadas pela historiografia.

Ao assumir a direção, a instituição encontrava-se desestruturada, com problemas internos como falta de recursos financeiros, salários atrasados, instalações deficitárias, corpo docente desestimulado e com problemas em relação aos campos de estágio, inclusive devido à escola manter-se atrelada à Escola de Enfermagem Anna Nery em uma posição de subalternidade. Em 21 de novembro de 1956, Lydia encaminha um ofício ao diretor do Serviço Nacional de 
Doenças Mentais, encimando o Regimento Interno da EEAP, solicitando a devida aprovação. O documento sinalizava a necessidade e urgência de encaminhamentos capazes de "sanar a deficiência que vem concorrendo para dificultar a direção da mesma" (Matta, 21 nov. 1956), permitindo inferir que sua nomeação para o cargo ocorreu à revelia de outros segmentos historicamente instituídos no bojo da enfermagem carioca, resistentes quanto à primazia da originalidade da escola no contexto nacional, bem como em relação à convocação da nova diretora, cuja nomeação inseria uma mulher negra no campo restritivo da formação superior (Moreira, Oguisso, 2005; Moreira, 1999).

Um dos primeiros atos efetivados por Lydia resultou na contratação de Edith de Magalhães Fraenkel, Maria Luiza Falcão, Letícia Villanova Freire e Cecília Ribeiro dos Santos, que fortaleceu o professorado existente, conferiu ânimo aos alunos desmotivados e desacreditados, bem como respaldo técnico-científico às suas propostas. A correspondência enviada pela nova diretora da Escola de Enfermagem Alfredo Pinto ao diretor do Serviço Nacional de Doenças Mentais considera a "Proposta de contrato" e dizia:

Senhor Diretor: A fim de completar o quadro de pessoal necessário ao progresso desta Escola, e em virtude da boa vontade de V.S. em ceder parte da Verba dessa Diretoria, solicito-lhe suas providências no sentido de propor o contrato das seguintes candidatas, cujos documentos estão relacionados em anexo. 1- D. Edith de Magalhães Fraenkel, como Orientadora. Uma vez que a Escola de Enfermagem Alfredo Pinto vai entrar em fase de reformas, necessita de uma pessoa de capacidade comprovada, tal seja a candidata em apreço, visto ter a mesma organizado a Escola de Enfermagem de São Paulo, que é por si um padrão para as outras Escolas do gênero. 2 - D. Maria Luiza Falcão, como chefe da Seção de Enfermagem. Não contando esta Escola, na sua estrutura com uma pessoa abalizada para responder por este Setor, um dos mais importantes da referida Escola, uma vez que ficará esta Chefe encarregada de fiscalizar o andamento das matérias e serem dadas e que constituem o currículo escolar. 3 - D. Leticia Villanova Freire e D. Cecília Ribeiro dos Santos, como Instrutoras. Necessitavam as alunas, quando no primeiro e segundo anos, de uma assistência permanente e rigorosa, não havendo nesta Escola nenhum cargo ou função correspondente e sendo urgente o seu preenchimento, pois a falta de instrutoras vem sendo a principal causa do pouco proveito e do comportamento dos alunos deste estabelecimento de ensino. Deverão as referidas candidatas serem contratadas na base de Cr\$ 4.000,00 (quatro mil cruzeiros) cada uma, uma vez que esta repartição não se acha em condições de dispensar nenhuma das funções solicitadas. Esclareço, outrossim, que os documentos relacionados se acham na Secretaria da Escola e serão encaminhados tão logo sejam solicitados. Aproveito a oportunidade para apresentar a V.S. meus protestos de estima e consideração. Lydia das Dôres Matta. Diretor (sic) da EEAP (Matta, 21 nov. 1956).

Edith de Magalhães Fraenkel, no final dos anos 1950, encontrava-se afastada da direção e da Escola de Enfermagem de São Paulo. ${ }^{3}$ Sua história de vida permite considerar que seu retorno para o Rio de Janeiro, muito provavelmente, provocou descontentamentos no âmbito das políticas de ensino e dos recursos destinados à enfermagem, ou ainda, que sua atuação na Escola Alfredo Pinto e os consequentes avanços que sua presença instauraria na depreciada escola resgatasse a historicidade sufocada, fazendo emergir a representação de pioneira no ensino de enfermagem do Brasil. 
Edith Fraenkel, "pioneira das pioneiras", como caracterizou Victória Secaf (Secaf, Costa, 2007), conhecia não somente a cidade como mantinha relacionamentos com elites locais, pois vinha de uma família de políticos e filantropos estabelecidos no Rio de Janeiro. Os relacionamentos existentes e mantidos poderiam não agradar grupos distintos filiados à Escola de Enfermagem Anna Nery, por exemplo, pois fariam expandir especificidades históricas para além do modelo padrão, retirando-a dos auspícios anteriormente estabelecidos durante a gestão de Maria de Castro Pamphiro, ex-aluna e vinculada à Escola Anna Nery.

A correspondência institucional assinada por Waleska Paixão, diretora da Escola Anna Nery, encaminhada nos primeiros momentos de sua gestão como resposta à manutenção da parceria entre as escolas, é reveladora dos desentendimentos. Acordos estabelecidos foram interrompidos logo após Lydia das Dôres Matta assumir a direção da Escola de Enfermagem Alfredo Pinto. Isso se confirma quando Wellington Amorim (Porto, Amorim, 2007) apresenta a existência de uma conexão direta entre as duas escolas, fortalecida por Maria de Castro Pamphiro, pessoa de confiança de Lays Netto dos Reys, além de aluna pioneira da Escola de Enfermagem Anna Nery, formada segundo padrões e representações do "ananerismo".

Outro aspecto envolvido nos rompimentos entre as parcerias anteriormente estabelecidas diz respeito à feminização da enfermagem brasileira, um dos pilares do "annanerismo". Foi uma das justificativas para a cisão entre as duas escolas no contexto de transição da direção de Maria de Castro Pamphiro e Lydia das Dôres Matta. Os impedimentos em relação ao gênero masculino, que também simboliza o padrão Anna Nery, recuperam o debate sobre a permanência de homens em cursos de enfermagem oferecidos pela Escola Alfredo Pinto, aspecto que, na gestão de Lydia, é caracterizado como problema, mas antes tolerado - o que subverte a ordem interna ao modelo exigido como padrão, da enfermagem como profissão para mulheres, e demonstra que havia um limite de tolerância de homens na profissão e que a relação de Maria de Castro Pamphiro com a Escola Anna Nery era diametralmente oposta. A transição da direção da escola para Lydia pode ser considerada, de modo sintomático, o motivo dos recuos nos acordos anteriormente estabelecidos entre as escolas cariocas, como permite entrever a correspondência entre as diretoras:

Senhora Diretora: Em atenção ao seu ofício do corrente mês, comunico-vos que os alunos que estão em estágio sob supervisão nesta escola, entrarão de férias a partir de dezembro próximo. No entanto a EEAP não poderá prescindir do auxílio sempre prestado pela Ana Néri ( $\mathrm{sic}$ ), e no próximo ano estudaremos uma maneira de os alunos em estágio serem acompanhados de uma instrutora. Aproveito a oportunidade para agradecer-vos a consideração dada a esta Escola e apresentar-vos meus protestos de estima e consideração; Lydia das Dôres Matta (Matta, nov. 1956).

Senhora Diretora: De há muito vimos sendo solicitadas por candidatos do sexo masculino, todas as vezes que abrimos matrículas para os cursos que mantemos. Sempre foi propósito da escola insistir nessa recusa, dadas as condições de acomodação, instalações, lotação de refeitórios etc., as quais nos tempos de hoje são exíguas até mesmo para o número de nossas alunas. Ao manter esse ponto não nos sentimos constrangidas, de vez que há várias escolas que aceitam rapazes, e assim, não estão, pois, fechadas a eles as portas da profissão. Quando começamos a receber alunas de 
outras escolas para estágios no nosso hospital, o grupo era integrado exclusivamente por moças. Com o correr dos tempos um ou outro rapaz foi aparecendo e, se não reclamamos em defesa dos nossos propósitos, foi porque, num esforço de tolerância, aceitamos a experiência, na esperança de que dois ou três deles não constituíssem distúrbio à ordem, pois o comportamento de grupos de minorias, via de regra, é coisa fácil de se controlar. Tal não se dá no momento: em grupo maior, os rapazes constituem sérios inconvenientes à disciplina do Pavilhão de Aulas e do Hospital - mal uniformizados (do ponto de vista higiênico) estacionam nas imediações do Hospital e do Pavilhão de Aulas, dando a quem passa uma impressão de certa familiaridade com as alunas o que realmente nos constrange. Sendo alunos externos e estagiando no HSFA, pouco contato deverão ter com a sua própria escola, que, a distância, se sentirá impotente frente aos abusos acima relatados, os quais já foram motivo de reclamações da própria Administração do H.S. Francisco. Temos para nós que melhor conviria o estágio e a supervisão dos mesmos a outra instituição que não tivesse a responsabilidade de formar moças. A experiência já nos mostrou a impossibilidade de continuar a recebê-los. Sendo assim, pedimos que essa providência vigore a partir de 3 de setembro próximo vindouro. Waleska Paixão (Paixão, nov. 1956).

Para além das questões de gênero, a transição que levou Lydia a assumir a direção da tradicional escola evoca turbulências outras como as enfrentadas junto ao campo de estágio e a falta de pagamento de professores, como previa a legislação vigente, ampliando dificuldades de manutenção da formação profissional com a qualidade desejada. A Escola de Enfermagem Alfredo Pinto se encontrava desacreditada devido à falta de pagamento adequado de professores e monitores, consequentemente, não mantendo compromisso com responsabilidades primordiais que atingiam aulas, estágios e cursos, problemas que geravam tensões permanentes.

As estratégias propostas para o restabelecimento da mais antiga escola carioca permitem considerar que Lydia detinha um conhecimento profundo das leis ou era muito bem assessorada, além de capacidade de enfrentamento a grupos opositores simbolicamente estabelecidos. Durante 15 anos de vigência do decreto-lei n.4.725, de 22 de setembro de 1942, os honorários não haviam sofrido qualquer alteração para uma melhor remuneração. Ainda que houvesse verbas, estas não poderiam ser redistribuídas para o aumento de salários devido à força da lei, que rigidamente determinava o valor da hora de trabalho, como atestam os indícios históricos:

A referida importância não chega nem para atender às exigências de transporte para os médicos, que têm em média 1 hora de aula por dia, muito menos para a compra de uma simples média com pão com manteiga, para as monitoras, que têm 7 horas de atividades diárias e não podem como as demais enfermeiras ter mais de um emprego. Ainda para criar mais embaraço à Direção da Escola, o orçamento em vigor não pode ser usado dentro do padrão da vida atual, apesar de existir verba, devido à situação do cito Decreto-Lei ... Uma vez modificados estes dois artigos, teremos oportunidade de contarmos com melhores dias para o futuro curricular, sem passarmos por problemas desagradáveis. Poderemos traçar um plano real de atividades para que o aluno não passe na Escola dois anos e meio fazendo curso de auxiliar de enfermagem em vez de dezoito meses e aluno de enfermagem não fique quatro anos na Escola em vez de três, atraso este decorrente da dificuldade de encontrar 'quem tenha uma hora vaga' em suas 
atividades, para vir ministrar aula por quarenta cruzeiros a hora, aos alunos da EEAP. Além da Escola ficar sujeita à hora vaga do professor, o aluno fica na expectativa da espera se terá aula ou não, reagindo de maneira pouco educada, a sua preocupação em ver o tempo passar e o curso parar, pois a evolução do mesmo é rítmica e contínua. As interrupções prejudicam a sua formação profissional, o seu interesse e principalmente o seu aproveitamento, em relação ao aprendizado, levando o aluno a uma grande indiferença. Decorrente deste grave e sério problema, é que a EEAP caiu no descrédito social, onde seus diplomados são alijados da esfera profissional, só sendo preferidos, quando não há absolutamente outro de outra escola, numa grande injustiça ao mesmo. Daí tentarmos dar oportunidade mais sadia ao aluno, para que ele possa ter um curso mais ou menos concreto, dentro do mínimo exigido pelas leis que regem o ensino da Enfermagem no País (Matta, 21 nov. 1956).

A Escola Alfredo Pinto encontrava-se em franco declínio institucional, situação provocada pela representação e domínio do padrão a que estavam submetidas escolas de enfermagem no Brasil, que excluíam homens e mulheres negras, assim como o ensino de enfermagem psiquiátrica da formação profissional. A substituição da direção à revelia de um posicionamento político atrelado à representação dominante da educação superior em enfermagem, de feminização da profissão, da divisão que o modelo anglosaxão atribuía ao gênero feminino e ao ensino da psiquiatria, atrelada a completa falta de recursos financeiros, que reiteram processos anteriores à sua gestão, contribuem para o prejuízo crescente da formação profissional oferecida pela escola e ampliam o abandono das funções docentes por parte dos professores e colaboradores, cujo resultado evidencia o baixo rendimento dos alunos e a fabricação de uma imagem negativa para o estabelecimento de ensino. Todavia, firme em seus propósitos de elevação das condições do ensino e de redimensionamento da condição institucional encontrada, Lydia assim caracterizava as condições da primeira escola de enfermagem brasileira:

A EEAP continua lutando com dificuldades monetárias, enquanto persistem os erros de legislação que devem ser sanados com urgência, uma vez que o problema de pagamento das enfermeiras vem sendo cada vez mais grave. Ainda mais agravado este ano com as novas normas adotadas no Tribunal de Contas ... Se levarmos em conta apenas o ritmo normal de estágios e aulas, poderemos dizer que a EEAP funcionou regularmente atendendo mais ou menos as suas finalidades precípuas. Mas aprofundando veremos que os problemas primordiais ainda se encontram sem solução ... Mas continuamos esperando e trabalhando a fim de que continue de pé a Escola que uma plêiade de médicos irmanados por um ideal e amor ao próximo criou em 27 de setembro de 1890, na Praia Vermelha, com o fim de dar um pouco de conforto e cuidados aos doentes sob sua responsabilidade, já que no Brasil ainda não existia nenhuma escola do gênero. No entanto, com raras exceções, os seus seguidores têm abandonado esse ideal, deixando que outras escolas passem à frente da primeira e tomem o nome de pioneira quando esse título deveria pertencer por direito de idade e também por ter sido a primeira escola de três anos curriculares (Matta, 21 nov. 1956).

Ao reiterar a primazia da escola, Lydia questionava o discurso dominante que anulava a experiência histórica da Escola de Enfermagem Alfredo Pinto. Apoiada por Edith de Magalhães Fraenkel, a nova diretora mantinha uma rede de contatos importantes, fazia uso de sua posição junto aos meios de comunicação como mecanismo para arregimentar 
candidatos, divulgando cursos com propagandas em jornais e rádio, como as veiculadas nos Jornal do Brasil e Jornal dos Sports, além de Rádio Federal, Rádio Ministério da Educação, Rádio e Televisão Tupi, "A Voz do Brasil", entre outros, efetivas para a manutenção e revitalização da primeira escola de enfermagem do Brasil.

Em sua gestão, Lydia das Dôres Matta renovou perspectivas de formação profissional executadas na Escola de Enfermagem Alfredo Pinto, tornando-se historicamente a diretora que reorganizou o ensino na tradicional escola carioca. Tirá-la do anomimato e referenciála restauram a historicidade do espaço de formação que hoje é abrigado pela Unirio. Como sinalizado, outros diretores foram alvos de estudos pela historiografia produzida por enfermeiros, ainda que prevaleça a atenção da memorialística em torno da escola (Porto, Amorim, 2007; Moreira, Oguisso, 2005).

Terminando seu trabalho na Escola de Enfermagem Alfredo Pinto, Lydia decidiu atender aos apelos feitos pelo presidente Juscelino Kubistchek para que fosse com o grupo pioneiro de funcionários públicos federais para o Distrito Federal, ajudar a transferir a capital do Rio de Janeiro para a inóspita região central do país.

A história de vida dessa ilustre inominada é constituída de aventuras e desafios, pois deixou o conforto da cidade do Rio de Janeiro para trabalhar com outros pioneiros na construção de Brasília, Distrito Federal. Somente com a instalação da administração na cidade, Lydia conseguiu ser nomeada para o Senado Federal. Registros sobre essa fase indicam que sua atuação foi fundamental, juntamente com Diva Câmera, na obtenção do terreno junto à Novacap para construção da sede própria da Aben (Carvalho, 2008). Desde o pedido inicial de doação feito por sua presidente, Maria Rosa Sousa Pinheiro, em 1958, ao projeto de construção da sede, Lydia estava presente, inclusive impedindo as várias tentativas de retomada do terreno por conta de atrasos na obra de construção (Carvalho, 2008).

Lydia não aparecia em fotos nem divulgava o que fazia. Raramente falava sobre seus familiares que haviam ficado no norte. Não se casou nem teve filhos, mas criou ao menos nove, a quem deu abrigo, educação e encaminhamento para a vida profissional. Diabética, perdeu a visão e, com a saúde abalada, fechou-se em um mundo particular, certamente honrada por ter cumprido o sonho de menina. Faleceu em Brasília com a quietude da discreta mas intensa vida que levou. Sua trajetória evoca uma mulher ímpar, trabalhadora incansável e dedicada ao exercício profissional, uma ilustre inominada, enfermeira que reergueu a primeira escola de enfermagem do Brasil, a mesma que, não por acaso, aceitava homens e mulheres negros.

\section{Considerações finais}

A história das mulheres negras invariavelmente é marcada por violências incomensuráveis e diz muito a respeito do Brasil. Suas trajetórias demarcam experiências singulares e traduzem relações de poder que desmantelam discursos herméticos, dogmáticos, além de ampliarem o debate sobre raça e classe no âmbito em que se inserem. Ao emergirem na contramão dos paradigmas dominantes, protagonismos, memórias e lugares, ao serem reestabelecidos, alteram realidades e identidades, e assim refazem o passado. 
Os estudos sobre o tema têm revisitado interpretações classicamente destinadas às mulheres negras, retirando-as das amarras que as condicionavam, sufocando-as ao subjugarem suas experiências (Nepomuceno, 2012; Xavier, Farias, Gomes, 2012; Brazil, Schumaher, 1998). A historiografia brasileira negligenciou a ação dessas mulheres, localizando-as na subalternidade, congelando-as em espaços aviltantes, ordinários, nos quais foram significadas como menores em relação à escala de valores que as excluíam como ilustres inominadas.

Ainda que lacunar, a história dessa protagonista negra da enfermagem brasileira é indicativa segura da resistência. A memória ora tangenciada permite refazer, ressignificar e desconstruir discursos existentes sobre as mulheres negras. A trajetória de Lydia das Dôres Matta evoca inquietações que exigem novas incursões sobre o tema, contudo, sua vida e trabalho traduzem o esforço contra a opressão permanente na sociedade brasileira, que vilipendia e restringe o reconhecimento das atuações de mulheres negras no mundo social mais amplo e não apenas na enfermagem.

\title{
NOTAS
}

\begin{abstract}
${ }^{1}$ A publicação do decreto-lei estadual n.13.040, de 31 de outubro de 1942, instituiu a Escola de Enfermagem da Universidade de São Paulo. Seu histórico evidencia acordos governamentais estabelecidos entre Brasil e EUA, mediados entre a Fundação Rockefeller e Estado de São Paulo, com vistas à modernização da saúde pública brasileira. Em sua primeira fase, denominava-se Escola de Enfermagem de São Paulo da Faculdade de Medicina da Universidade de São Paulo, por configurar-se como unidade de ensino anexa à Faculdade de Medicina. Em 1956 foram iniciadas as gestões para a desanexação, processo efetivado com a publicação do decreto estadual n.42.809/63, em dezembro de 1963. A partir dessa data, a escola passou a ser um estabelecimento de ensino superior denominado Escola de Enfermagem da Universidade de São Paulo (EEUSP) (Carvalho, 1980; Mott, 1999).
\end{abstract}

${ }^{2}$ A historiografia compulsada aponta que em março de 1942, na cidade de Washington, Getúlio Vargas e Franklin Roosevelt assinaram um acordo bilateral. No conjunto de trinta tratados de cooperação técnica, econômica e militar, que confirmou a coalizão do Exército Brasileiro aos aliados americanos na Segunda Guerra Mundial, havia uma cláusula que estipulava o apoio à política de saúde e saneamento, que exigia a fundação do Serviço Especial de Saúde Pública (Sesp). Patrocinado pelo Instituto de Assuntos Interamericanos (Iaia), o Sesp obteve autonomia financeira, organizacional e política perante o Departamento Nacional de Saúde Pública (DNSP), iniciando um movimento interno de recuperação de áreas sociais degradadas, bem como a profilaxia de doenças infectocontagiosas, redimensionando políticas públicas, assim como a qualificação profissional no âmbito da saúde. Norteado por essas preocupações, em julho de 1942, o Sesp foi estabelecido com estatuto jurídico especial e autonomia em relação ao Ministério da Educação e Saúde (Tota, 2000).

${ }^{3}$ Edith de Magalhães Fraenkel havia trabalhado como instrutora da Escola Anna Nery (1926-1927), enfermeira-chefe do Serviço de Tuberculose do Departamento de Saúde Pública, enfermeira-chefe de Saúde Pública do DNSP (1928), diretora da Divisão de Enfermagem do Serviço de Enfermagem do DNSP (1929/1931), superintendente geral do Serviço de Enfermagem do DNSP (1929/1940) e diretora da Escola de Enfermagem da Universidade de São Paulo (1942-1955). Seu currículo atestava o grau de importância e a influência que poderia estabelecer pela notoriedade social que agregaria a EEAP. Pioneira nos caminhos do movimento associativo, criou a Associação Brasileira das Enfermeiras Diplomadas (Abed) quando ainda vivia no ambiente carioca.

\section{REFERÊNCIAS}

ANDREWS, George Reid.

Negros e brancos em São Paulo, 1888-1988. Bauru: Edusc. 1998.
BARREIRA, Ieda de Alencar.

Os primórdios da enfermagem moderna no Brasil. Escola Anna Nery. Revista de Enfermagem, n. de lançamento, p.161-176. 1997. 
BERTUCCI, Liane Maria; MOTA, André;

SCHRAIBER, Lilia Blima (Org.).

Saúde e educação: um encontro plural. Rio de

Janeiro: Editora Fiocruz. 2017.

BICUDO, Virgínia Leone.

Atitudes raciais de pretos e mulatos em São Paulo. In: Maio, Marcos Chor (Org.). São Paulo: Editora Sociologia e Política. 2010.

BOMBAS...

Bombas voadoras fornecidas ao Brasil. Folha da Noite, capa. 24 jun. 1947.

BRAZIL, Erico Vital; SCHUMAHER, Schuma. Mulheres negras do Brasil. São Paulo: Editora Senac. 1998.

CAMPOS, André Luiz Vieira de.

Políticas internacionais de saúde na Era Vargas: o

Serviço Especial de Saúde Pública, 1942-1960.

Rio de Janeiro: Editora Fiocruz. 2006.

CARVALHO, Amália Corrêa de.

Edith de Magalhães Fraenkel. São Paulo: Escola de Enfermagem/USP. 1992.

CARVALHO, Amália Corrêa de.

A Escola de Enfermagem da Universidade de São Paulo: resumo histórico, 1942-1980. São Paulo: Escola de Enfermagem/USP. 1980.

CARVALHO, Anayde Corrêa de.

Associação Brasileira de Enfermagem 1926-1976.

Documentário. Brasília: Aben. 2008.

CASTRO SANTOS, Luis Antônio de; FARIA, Lina

Rodrigues de.

A cooperação internacional e a enfermagem de saúde pública no Rio de Janeiro e São Paulo. Horizontes, v.22, n.2, p.123-148. 2005.

CERTEAU, Michel de.

A invenção do cotidiano: as artes do fazer.

Petrópolis: Vozes. 1994.

COISAS...

Coisas do HC. O Bisturi, p.5. abr. 1947.

CYTRYNOWICZ, Roney.

A serviço da pátria: a mobilização das enfermeiras no Brasil durante a Segunda Guerra Mundial. História, Ciências, Saúde - Manguinhos, v.7, n.1, p.73-91. 2000.

DAVIS, Angela.

Mulheres, raça e classe. São Paulo: Boitempo. 2016.

DEANE, Leônidas.

Esboço histórico do Instituto Evandro Chagas. Revista da Fundação Sesp, n.31, p.47-56. 1986.

DONAHUE, Patricia.

Nursing: the finest art: an illustrated history. St. Louis: Mosby. 1996.
FARIA, Lina.

Educadoras sanitárias e enfermeiras de saúde pública: identidades profissionais em construção. Cadernos Pagu, n.27, p.173-212. 2006.

FICHA...

Ficha de admissão na Escola de Enfermagem da Faculdade de Medicina da Universidade de São Paulo (Arquivo do Setor de Graduação da Escola de Enfermagem da Universidade de São Paulo, São Paulo). fev. 1942.

FIGUEIREDO, Regina Érika Domingos de. Cuidar da saúde do vizinho: atuação do antropólogo Charles Wagley no Serviço Especial de Saúde Pública. História, Ciências, Saúde Manguinhos, v.21, n.4, p.1417-1436. 2014.

GALLOTTI, Odilon Vieira.

Carta ofício à Lydia das Dôres Matta.

Laboratório de Pesquisa em História da

Enfermagem da Universidade Federal do Estado do Rio de Janeiro, Rio de Janeiro. 23 nov. 1956.

GOMES, Flavio; CUNHA, Olívia Maria Gomes da.

Quase cidadão: histórias e antropologias da pósemancipação no Brasil. Rio de Janeiro: FGV Editora. 2007.

HALL, Stuart.

A identidade cultural na pós-modernidade. Rio de Janeiro: DP\&A. 2009.

JESUS, Carolina Maria de.

Quarto de despejo: diário de uma favelada. São Paulo: Ática. 2015.

MATTA, Lydia das Dôres.

Carta ao diretor do Serviço Nacional de Doenças Mentais. Laboratório de Pesquisa em História da Enfermagem da Universidade Federal do Estado do Rio de Janeiro, Rio de Janeiro. 4 dez. 1956

MATTA, Lydia das Dôres.

Carta ao diretor do Serviço Nacional de Doenças Mentais. Laboratório de Pesquisa em História da Enfermagem da Universidade Federal do Estado do Rio de Janeiro, Rio de Janeiro. 21 nov. 1956.

MATTA, Lydia das Dôres.

Carta à Waleska Paixão, diretora da Escola de Enfermagem Anna Nery. Laboratório de Pesquisa em História da Enfermagem da Universidade Federal do Estado do Rio de Janeiro, Rio de Janeiro. nov. 1956.

MOREIRA, Almerinda; OGUISSO, Taka.

Profissionalização da enfermagem brasileira. Rio de Janeiro: Guanabara Koogan. 2005.

MOREIRA, Martha Cristina Nunes.

A Fundação Rockefeller e a construção da identidade profissional de enfermagem no Brasil 
na Primeira República. História, Ciências, Saúde Manguinhos, v.5, n.3, p.621-645. 1999.

MOTT, Maria Lucia Barros.

Discutindo a história da enfermagem em São Paulo, 1890-1920. Cadernos Pagu, v.13, p.327355. 1999.

MOWBREY, Patrícia.

Florence Nightingale Museum: guide book. London: The Florence Nightingale Museum Trust. 1997.

NEPOMUCENO, Bebel.

Protagonismo ignorado. In: Pinsky, Carla Bassanezi; Pedro, Maria Joana (Org.). Nova história das mulheres. São Paulo: Contexto. p.382-409. 2012.

OGUISSO, Taka; DUTRA, Vanderli de Oliveira; SOUZA CAMPOS, Paulo Fernando de.

Cruz Vermelha Brasileira, filial estado de São Paulo: formação em tempos de paz. São Paulo: Manole. 2008.

PAIXÃO, Waleska.

Carta à Lydia das Dôres Matta, diretora da Escola de Enfermagem Alfredo Pinto. Laboratório de Pesquisa em História da Enfermagem da Universidade Federal do Estado do Rio de Janeiro, Rio de Janeiro. nov. 1956.

PORTO, Fernando Rocha; AMORIM, Wellington.

História da enfermagem brasileira. Rio de Janeiro: Águia Dourada. 2007.

RESUMO...

Resumo dos estágios práticos da Escola de Enfermagem da Faculdade de Medicina da Universidade de São Paulo (Arquivo do Setor de Graduação da Escola de Enfermagem da Universidade de São Paulo, São Paulo). jan. 1946.

SANTIAGO, Emiliane.

Tradição e modernidade: desanexação da Escola de Enfermagem da Universidade de São Paulo. Dissertação (Mestrado em Enfermagem) Universidade de São Paulo, São Paulo. 2011.

SECAF, Victoria; COSTA, Hebe.

Enfermeiras do Brasil: história das pioneiras. São Paulo: Martinari. 2007.
SOUZA CAMPOS, Paulo Fernando de. Enfermeiras da Legião Negra: representações da enfermagem na Revolução Constitucionalista de 1932. Faces de Eva: Estudos sobre a Mulher, n.33, p.53-66. 2015.

SOUZA CAMPOS, Paulo Fernando de.

Memorial de Maria de Lourdes Almeida: história e enfermagem no Brasil pós-1930. História, Ciências, Saúde - Manguinhos, v.20, n.2, p.609625. 2013.

SOUZA CAMPOS, Paulo Fernando de. Programa Enfermagem do Sesp: formação e identidade profissional brasileira pós-1930. Cadernos de História da Ciência, v.8, n.1, p.77-90. 2012.

SOUZA CAMPOS, Paulo Fernando de.

Los negros y los cuidados en las familias de Brasil: una visión histórica e iconográfica. Cultura de los Cuidados: Revista de Enfermería y Humanidades, ano 12, n.24, p.26-34. 2008.

SOUZA CAMPOS, Paulo Fernando de; OGUISSO, Taka.

Enfermagem no Brasil: formação e identidade profissional pós-1930. São Paulo: Yendis. 2013.

SOUZA CAMPOS, Paulo Fernando de; OGUISSO, Taka.

A Escola de Enfermagem da Universidade de São Paulo e a reconfiguração da identidade profissional da enfermagem brasileira. Revista Brasileira de Enfermagem, v.61, n.6, p.892-898. 2008.

TERMO...

Termo de concessão de bolsa Serviço Especial de Saúde Pública. Arquivo do Setor de Graduação da Escola de Enfermagem da Universidade de São Paulo, São Paulo. fev. 1942.

TOTA, Antônio Pedro.

O imperialismo sedutor: a americanização do Brasil na época da Segunda Guerra. São Paulo: Companhia das Letras. 2000.

VELANDIA MORA, Ana Luisa.

Historia de la enfermería en Colombia. Bogota: Universidad Nacional de Colombia. 1995.

XAVIER, Giovana; FARIAS, Juliana Barreto; GOMES, Flávio (Org.).

Mulheres negras no Brasil escravista e do pósemancipação. São Paulo: Selo Negro. 2012.

\section{$\rightarrow \rightarrow \rightarrow<<<$}

